\title{
Environmental effects on asexual reproduction rates of the scyphozoan Aurelia labiata
}

\author{
Jennifer E. Purcell* \\ Western Washington University, Shannon Point Marine Center, 1900 Shannon Point Road, Anacortes, Washington 98221, USA
}

\begin{abstract}
Problem outbreaks of jellyfish and warming of the Earth's climate are both being reported at unprecedented rates. Models forecast continued changes in temperature, salinity, and solar radiation (insolation) in the world's oceans as consequences of global warming. Many species with a swimming jellyfish stage also have a benthic stage that asexually produces buds and new jellyfish (ephyrae). This perennial benthic stage probably determines the numbers of jellyfish in the population. In this study, polyps of the moon jellyfish Aurelia labiata from Puget Sound, Washington, USA, were tested in 9 combinations of temperature $\left(7,10,15^{\circ} \mathrm{C}\right)$ and salinity $(20,27,34)$ in the dark, and in 9 combinations of photoperiod $\left(12,8\right.$, and $\left.4 \mathrm{~h} \mathrm{~d}^{-1}\right)$ and light intensity (1 screen, 2 screens, opaque) at ambient salinity (27) and temperature $\left(15^{\circ} \mathrm{C}\right)$. Another experiment tested polyps in treatments of 10,15 , and $20^{\circ} \mathrm{C}$. Survival of the initial polyps in all treatments was high (83 to $100 \%$ ). Temperature, salinity, and their combination dramatically affected the numbers of ephyrae produced (from nearly 0 at $7^{\circ} \mathrm{C}$ to 42 ephyrae polyp ${ }^{-1}$ at $15^{\circ} \mathrm{C}$ ), the percentages of ephyrae out of total asexual reproduction $\left(\leq 12 \%\right.$ at $7^{\circ} \mathrm{C}$ to $89 \%$ at $\left.20^{\circ} \mathrm{C}\right)$, and the delay before ephyra production $\left(>81 \mathrm{~d}\right.$ at $7^{\circ} \mathrm{C}$ but only 39 to $46 \mathrm{~d}$ at $15^{\circ} \mathrm{C}$ ). Thus, all results showed that more jellyfish were produced with increasing temperature. Long photoperiod and highest light intensity greatly accelerated strobilation, with polyps in $12 \mathrm{~h}$ light strobilating 30 to $40 \mathrm{~d}$ before those in other treatments. Polyps receiving the most light strobilated most frequently. In situ conditions showed that light increased much more rapidly than temperature before strobilisation, suggesting that light may be the more important signal. I suggest that the light-sensitive hormone melatonin, or a precursor like serotonin, coordinates the timing of strobilation in A. labiata with the seasonal light cycle.
\end{abstract}

KEY WORDS: Global warming $\cdot$ Temperature $\cdot$ Salinity $\cdot$ Photoperiod $\cdot$ Light $\cdot$ Jellyfish $\cdot$ Zooplankton Bloom · Climate

Resale or republication not permitted without written consent of the publisher

\section{INTRODUCTION}

Outbreaks of gelatinous zooplankton species can have detrimental effects on human enterprise (reviewed by Purcell et al. 2007). For example, outbreaks of the jellyfish Pelagia noctiluca in the Mediterranean Sea affects human health and recreation; the ctenophore Mnemiopsis leidyi, which was accidentally introduced into the Black and Caspian Seas, has been blamed for depleting fish stocks; the jellyfish Aurelia aurita has interrupted power plant operations; several species have caused mass mortalities of fish in aquaculture pens; and jellyfish in high biomass have damaged commercial fisheries by clogging nets in many regions. The importance of gelatinous species as predators of zooplankton and ichthyoplankton has been demonstrated repeatedly (reviewed by Purcell \& Arai 2001).

An unprecedented number of jellyfish outbreaks was reported in the 1990s and 2000s, which may be due to a combination of climate effects and anthropogenic modification of the environment (reviewed in Purcell et al. 2007). Many authors have speculated that such changes may benefit jellyfish populations (e.g. Mills 2001, Parsons \& Lalli 2002), but actual studies are few. Recent correlations of gelatinous predator populations with climate variables make a compelling case for 
the importance of climate in determining their population sizes (reviewed by Purcell 2005, Purcell et al. 2007). Long-term records of gelatinous predator abundances have provided invaluable data that show variation with climate conditions. For most of the temperate species studied, large populations have occurred in warm conditions. Similarly, the most recent reports of unusual occurrences of jellyfish are associated with increasing ocean temperatures in those regions (Uye \& Ueta 2004, S. Uye unpubl.). Given that climate models project global ocean warming for the foreseeable future (e.g. Alley et al. 2007), jellyfish populations may be expected to increase (Attrill et al. 2007).

Population sizes of many jellyfish probably reflect the success of the benthic polyp stage in producing jellyfish. The life cycle of most scyphomedusae and many hydromedusae includes a perennial clonal polyp stage that asexually buds more polyps and new jellyfish. For scyphozoans, the production of new jellyfish (ephyrae) is called strobilation. Control of the jellyfish populations does not appear to be at the adult stage. Populations of large jellyfish, such as Aurelia aurita, are not obviously reduced by predation (reviewed most recently by Arai 2005). Gelatinous predators shrink rather than die when unfed, and can regrow after long periods of limited food conditions (Hamner \& Jenssen 1974).

Temperature has a great effect on variations of jellyfish populations (Purcell 2005, Purcell et al. 2007). Most species (13 of 16 species examined) have large populations in warm conditions; however, jellyfish of 3 species were reduced in unusually warm conditions (tropical Mastigias sp., Dawson et al. 2001; mesopelagic, holoplanktonic Colobonema sericeum, Raskoff 2001; and subarctic Chrysaora melanaster, Brodeur et al. in press). Experiments conducted on temperate species show greatly increased total asexual reproduction in response to warm temperatures, with the proportion of new jellyfish increasing over that of buds (Purcell et al. 1999, Ma \& Purcell 2005).

Salinity also is an important factor, especially for estuarine species. Population blooms of Chrysaora quinquecirrha jellyfish in Chesapeake Bay and of jellyfish in the Yangtze River estuary were related to high salinity conditions (Cargo \& King 1990, Purcell \& Decker 2005, Xian et al. 2005). High populations of non-estuarine species have also been correlated with high salinities (Goy et al. 1989, Molinero et al. 2005). Laboratory experiments showed greater asexual reproduction by Rhopilema esculenta polyps in high salinity (Lu et al. 1989), by C. quinquecirrha polyps in intermediate salinity (Purcell et al. 1999), and by Moerisia lyonsi polyps in low salinity (Ma \& Purcell 2005).

Sunlight is important to most organisms on Earth. It is the source for most production (e.g. Wild et al. 2005,
Behrenfeld et al. 2006). It is a key regulating factor for daily (e.g. vertical migration and spawning) and seasonal (e.g. reproduction) rhythms, and for orientation and navigation of many organisms (e.g. Honegger et al. 1980, Hamner et al. 1994, Hardeland 1997, Naylor 2006). The amount of sunlight that reaches the Earth's surface is changing due to the effects of human activities (Pallé \& Butler 2002, Wild et al. 2005).

Much of the earlier work on scyphozoan polyps sought to determine the stimuli for strobilation (for reviews, see Spangenberg 1968, Arai 1997, Lucas 2001). Changes in several factors, including temperature, food, and light, seemed to trigger strobilation in Aurelia aurita polyps (e.g. Ishii \& Watanabe 2003). Sparse data suggested that light might be an important factor in scyphozoan strobilation. Custance (1964) stated that light ( $6 \mathrm{~h} \mathrm{~d}^{-1}$, intensity not measured) inhibited strobilation in A. aurita, but contrary to his conclusions, the greatest production of ephyrae occurred in one group in light. For Chrysaora quinquecirrha polyps, which strobilate in situ in spring as temperatures and light increase, strobilation accelerated with longer periods of light $(0 \mathrm{~h}, 10 \mathrm{~h}, 24 \mathrm{~h}$, intensity not measured; Loeb 1973). These seemingly contradictory results may have confused the role of light. Only 3 studies have considered the possible role of light on jellyfish populations in situ (Hernroth \& Grøndahl 1985, Molinero et al. 2005, Purcell \& Decker 2005). By comparison, the importance of temperature and salinity to jellyfish has been studied more, as described above (reviewed by Purcell 2005, Purcell et al. 2007).

Moon jellyfish in the genus Aurelia have a global distribution and are responsible for problem blooms in many areas. Aurelia labiata is a native species in the northeast Pacific from central California to the Gulf of Alaska. In this study, I quantified budding and ephyra production rates of $A$. labiata polyps in response to combinations of temperature and salinity, and in combinations of light intensity and duration (photoperiod). The null hypotheses tested were that temperature, salinity, and light intensity or duration do not affect the numbers of buds or ephyrae produced, or the timing of strobilation.

\section{MATERIALS AND METHODS}

Temperature-salinity (T-S) experiments (Expts 1 and 2). Attached polyps, grown from sexuallyproduced planulae released by Aurelia labiata jellyfish from Hood Canal, Washington, USA, were provided by the Seattle Aquarium. On 21 November 2004, 1 polyp was placed in each well of 6 -well polycarbonate culture plates with $10 \mathrm{ml}$ of $5 \mu \mathrm{m}$ filtered seawater and allowed to attach. Each treatment in Expt 1 included 
24 polyps. The 9 treatments consisted of 3 temperatures $\left(7,10,15^{\circ} \mathrm{C}\right)$ maintained by 3 Percival Intellus environmental controllers ('incubators'), and 3 salinities $(20,27,34)$ in each incubator. These treatments were chosen to test responses at the extremes of local environmental conditions, with 10 to $12^{\circ} \mathrm{C}$ and 27 salinity being typical conditions beneath the surface layer (J. Purcell unpubl. data). A previous experiment indicated poor activity of polyps at $5^{\circ} \mathrm{C}$ (G. Arrondondo \& J. Purcell unpubl. data). Temperatures were measured in the incubators by Onset temperature loggers, which showed little variation within each incubator (SE of readings over $2 \mathrm{wk}$ were 0.03 to $0.04^{\circ} \mathrm{C}$ ). Stock solutions at experimental salinities were made from $5 \mu \mathrm{m}$ filtered ambient seawater (salinity 27) by dissolving InstantOcean ${ }^{\circledR}$ or by adding reverse-osmosis water to achieve final salinities of 34 and 20, respectively. Salinities were measured with a YSI ${ }^{\circledR}$ temperaturesalinity meter. Lights were off in the incubators. Newly hatched Artemia salina nauplii were fed in excess twice weekly. After the polyps fed for 1 to $3 \mathrm{~h}$, the wells were cleaned with swabs; seawater and uneaten food were discarded and replaced with filtered seawater of the same temperature and salinity. This feeding protocol was intended to provide saturating prey briefly, resulting in equal feeding in all treatments by minimizing enhanced feeding at warmer temperatures (Ma \& Purcell 2005). The numbers of buds and ephyrae were counted for each polyp beginning when the first signs of strobilation were observed (Day 0). After enumeration, ephyrae and buds that had detached from the initial polyps were removed.

In order to test if high temperature was detrimental to polyp survival or reproduction, a second experiment (Expt 2) was run from 17 July to 15 November 2006. Polyps were obtained from the Seattle Aquarium. Eighteen polyps were placed in all treatments, which consisted of 3 temperatures $\left(10,15,20^{\circ} \mathrm{C}\right)$ maintained in the same incubators. Identical maintenance and data-collection protocols were followed as before.

Light intensity and duration experiment (Expt 3). In situ light levels were measured (in $\mu \mathrm{mol}$ photons $\mathrm{s}^{-1}$ $\mathrm{m}^{-2}$ ) using a LiCor LI-193SA Spherical Quantum sensor and in lux (= lumens $\mathrm{m}^{-2}$ ) using Onset light and temperature loggers under floats beneath a covered marina in Cornet Bay, Washington, USA, where Aurelia labiata polyps occur in great numbers. Light levels in the experiment were chosen accordingly.

Three incubators were equipped with 2 shelves having one new, natural-spectrum bulb spanning their width in the center. Equal intensities of light on each shelf were obtained by attaching strips of black electrical tape to the bulbs. Light intensities (in $\mu \mathrm{mol}$ photons $\mathrm{s}^{-1} \mathrm{~m}^{-2}$ ) were measured at the start of the experiment using a Biospherical Instrument QSL-100 light meter. During the experiment, light (lux) and temperature $\left({ }^{\circ} \mathrm{C}\right)$ were recorded every $5 \mathrm{~min}$ in the treatments using Onset light and temperature loggers; hence the daily light levels reported represent the sum of 288 readings.

Aurelia labiata jellyfish from East Sound, Washington, USA, were maintained in a 3001 clear plexiglass kreisel with continuous, $5 \mu \mathrm{m}$ filtered seawater inflow, and fed with Artemia salina nauplii. Attached polyps grown from released planulae were harvested on 17 June 2004 from the sides of the kreisel. Polyps were placed in individual wells in 6-well polycarbonate culture plates with $10 \mathrm{ml}$ of $5 \mu \mathrm{m}$ filtered seawater at 27 salinity and $12^{\circ} \mathrm{C}(\mathrm{n}=18$ polyps per treatment). Polyps were kept without food in a $12^{\circ} \mathrm{C}$ incubator under black plastic (4 layers of 0.85 mil plastic) prior to the start of the experiment on 24 June 2004 (Day 0), when the polyps were distributed among 9 light treatments in 3 incubators. Before harvest, polyps had been exposed to light from an external window and fluorescent room light, totaling $43715 \pm 12702$ lux d$^{-1}$. Therefore, the first strobilation cycle was considered to reflect light exposure prior to the experiment.

Each incubator $\left(12^{\circ} \mathrm{C}\right)$ maintained the photoperiod $\left(12,8\right.$, or $4 \mathrm{~h}$ light $\left.\mathrm{d}^{-1}\right)$. Three light intensity treatments in each incubator were created from 1 layer (the '1-screen' treatment) and 2 layers ('2 screens') of neutral-density plastic screen and 4 layers of 0.85 mil black plastic ('opaque') covering the polyp plates and Onset loggers. The screened treatments approximated light intensities under the marina dock (see Table 3), and the opaque treatments were dark.

Identical feeding, cleaning, and data-collection protocols were followed as before, but with all treatments maintained in $12^{\circ} \mathrm{C}$ and 27 salinity water. During data collection and cleaning, polyps were exposed to minimized room light from one indirect ceiling fluorescent light, and from the fiber-optic microscope lights, which were covered with red plastic to reduce light effects. Each well-plate was exposed to these lights for approximately $10 \mathrm{~min}$ twice weekly. The hatch of Artemia salina failed on Days 134 and 137 of the experiment.

Statistical analysis. The numbers of surviving and strobilating polyps were compared among treatments using chi-squared tests. For experiments testing 2 factors, if the data passed tests for normality and equality of variances, they were analyzed by 2-way analysis of variance (ANOVA). If the overall ANOVA results were significant, Bonferroni pair-wise comparisons were calculated. If the data failed normality or equal variance tests, they were analyzed by a non-parametric Kruskal-Wallis 1-way ANOVA on ranks, and pairwise comparisons were by Dunn's method. For Expt 2, testing temperature only, the data were analyzed similarly, but by 1-way ANOVAs. 


\section{RESULTS}

\section{Temperature-salinity (T-S) experiments}

Surface water temperatures in Puget Sound, Washington, where Aurelia labiata jellyfish and polyps occur, have surface lows of about $7^{\circ} \mathrm{C}$ in winter and highs of about $15^{\circ} \mathrm{C}$ in summer, while sub-thermocline waters typically remain about $12^{\circ} \mathrm{C}$ year round. Salinities reach up to about 30 , with reduced surface salinities occurring near rivers and after rainstorms (to <20); subsurface salinities show less variation and are typically about 27 . Thus, the polyps in combinations of temperature $\left(7,10,15^{\circ} \mathrm{C}\right)$ and salinity $(20,27,34)$ were exposed to environmentally reasonable conditions, with the mid-level treatment $\left(\mathrm{T}-\mathrm{S}: 10^{\circ} \mathrm{C}-27\right)$ representing typical conditions.

Polyps had high survival during Expt 1 (83.3 to $100 \%$ ). Survival was somewhat poorer at $7^{\circ} \mathrm{C}$, especially at high salinity (Table 1); however, differences were not significant among treatments ( $p>0.05$ ). Polyps began producing buds immediately after attaching in the experimental wells. The fewest buds were produced in the lowest
T-S combination $\left(7^{\circ} \mathrm{C}-20,4.5\right.$ buds polyp $\left.{ }^{-1}\right)$ and the most in $7^{\circ} \mathrm{C}-27$ (11.8 buds polyp ${ }^{-1}$ ), with other treatments averaging about 7 to 11 buds polyp ${ }^{-1}$. Fewer buds were produced at $15^{\circ} \mathrm{C}$ than at $10^{\circ} \mathrm{C}$. The total numbers of buds produced differed among treatments (Table 1, Fig. 1), with temperature, salinity, and their interaction having significant effects (all $\mathrm{p}<0.01$ ).

The numbers of polyps that strobilated differed significantly among treatments (Table 1). Few polyps (9 to $21 \%$ ) strobilated in the $7^{\circ} \mathrm{C}$ treatments, and none strobilated at $7^{\circ} \mathrm{C}-34$. Somewhat more polyps strobilated at 27 salinity, and generally fewer strobilated at 34 . The numbers strobilating were high (83 to $91 \%$ ) in $10^{\circ} \mathrm{C}-27,10^{\circ} \mathrm{C}-34$, and all $15^{\circ} \mathrm{C}$ treatments.

Warmer temperatures shortened the time until strobilation (Table 1). Polyps required $>80 \mathrm{~d}$ before strobilating at $7^{\circ} \mathrm{C}$, but only half that time at $15^{\circ} \mathrm{C}$. Strobilation occurred somewhat later at low salinity (20) than at intermediate salinity (27). The effects of temperature and salinity were significant (both $\mathrm{p}<0.004$ ); interaction effects could not be tested because of missing data (non-strobilating polyps). By accelerating the process of strobilation, warm temperatures increased the

Table 1. Aurelia labiata. Number of polyps producing ephyrae (strobilating) and the number surviving in 9 combinations of temperature and salinity during a $142 \mathrm{~d}$ experiment (Expt 1). Strobilation frequencies differed significantly among treatments, but survival was not significantly different (chi-squared tests). Two-way ANOVAs showed that temperature (T), salinity (S), and their interaction $(\mathrm{T} \times \mathrm{S})$ had significant effects on other measures of asexual reproduction. Significantly different pair-wise comparisons are indicated by different letters $(\mathrm{a}, \mathrm{b}, \mathrm{c}, \mathrm{d})$

\begin{tabular}{|c|c|c|c|c|c|c|}
\hline \multirow[t]{2}{*}{ Salinity } & \multicolumn{3}{|c|}{ Temperature } & \multirow[t]{2}{*}{ Test statistic } & \multirow{2}{*}{\multicolumn{2}{|c|}{$\mathrm{p}$ value }} \\
\hline & $7^{\circ} \mathrm{C}$ & $10^{\circ} \mathrm{C}$ & $15^{\circ} \mathrm{C}$ & & & \\
\hline \multicolumn{7}{|c|}{ Strobilating/surviving polyps } \\
\hline 20 & $2 / 22$ & $6 / 24$ & $21 / 24$ & \multirow[t]{3}{*}{$\chi_{4}^{2}=10.71 / \chi_{4}^{2}=0.325$} & \multirow{3}{*}{\multicolumn{2}{|c|}{$\mathrm{p}<0.05 / \mathrm{NS}$}} \\
\hline 27 & $5 / 24$ & $19 / 24$ & $21 / 23$ & & & \\
\hline 34 & $0 / 20$ & $21 / 24$ & $15 / 18^{*}$ & & & \\
\hline \multicolumn{7}{|c|}{ Mean no. of buds polyp ${ }^{-1}$ (SE) } \\
\hline 20 & $4.5(0.8) \mathrm{a}$ & $10.5(1.5) \mathrm{b}$ & $8.2(1.0) \mathrm{ac}$ & $\mathrm{T} F_{2,194}=10.005$ & $\mathrm{~T}$ & $\mathrm{p}<0.001$ \\
\hline 27 & $11.8(1.2) \mathrm{b}$ & $10.9(1.1) \mathrm{b}$ & $7.4(0.6) \mathrm{c}$ & $\mathrm{S} F_{2,194}=4.666$ & $\mathrm{~S}$ & $p=0.01$ \\
\hline 34 & $8.0(1.4) \mathrm{C}$ & $8.9(0.7) \mathrm{b}$ & $7.2(0.9) \mathrm{ac}$ & $\mathrm{T} \times \mathrm{S} F_{4,194}=9.514$ & $\mathrm{~T} \times \mathrm{S}$ & $\mathrm{p}<0.001$ \\
\hline \multicolumn{7}{|c|}{ Mean no. of days until first strobilation (SE) } \\
\hline 20 & $84.0(8.2)$ & $64.3(3.2)$ & $46.4(3.1)$ & $\mathrm{T} F_{2,106}=58.426$ & $\mathrm{~T}$ & $\mathrm{p}<0.001$ \\
\hline 27 & $82.0(2.0)$ & $49.0(2.3)$ & $39.3(0.9)$ & $\mathrm{S} F_{2,106}=5.796$ & $\mathrm{~S}$ & $p=0.004$ \\
\hline 34 & No strobilation & $54.8(2.1)$ & $43.3(3.3)$ & & & \\
\hline \multicolumn{7}{|c|}{ Mean no. of strobilations polyp ${ }^{-1}$ (SE) } \\
\hline 20 & $0.3(0.1) \mathrm{a}$ & $0.2(0.1) \mathrm{a}$ & $1.7(0.2) \mathrm{ac}$ & $\mathrm{T} F_{2,194}=115.919$ & $\mathrm{~T}$ & $\mathrm{p}<0.001$ \\
\hline 27 & $0.2(0.1)$ a & $0.8(0.4) \mathrm{b}$ & $1.6(0.1) \mathrm{c}$ & $\mathrm{S} F_{2,194}=0.582$ & & $\mathrm{~S}$ NS \\
\hline 34 & $0(0) \mathrm{a}$ & $0.8(0.5) \mathrm{b}$ & $1.8(0.2) \mathrm{C}$ & $\mathrm{T} \times \mathrm{S} F_{4,194}=3.780$ & $\mathrm{~T} \times \mathrm{S}$ & $\mathrm{p}=0.006$ \\
\hline \multicolumn{7}{|c|}{ Mean no. of ephyrae polyp ${ }^{-1}$ (SE) } \\
\hline 20 & $17.0(2.0) \mathrm{a}$ & $21.3(3.4) \mathrm{b}$ & $32.1(4.0) \mathrm{C}$ & $\mathrm{T} F_{2,194}=57.208$ & $\mathrm{~T}$ & $\mathrm{p}<0.001$ \\
\hline 27 & $23.8(7.3) \mathrm{ab}$ & $30.6(2.3) \mathrm{C}$ & $34.2(4.4) \mathrm{C}$ & $\mathrm{S} F_{2,194}=4.067$ & $\mathrm{~S}$ & $\mathrm{p}<0.02$ \\
\hline 34 & $0.0(0.0)$ a & $22.2(8.7) \mathrm{b}$ & $41.7(5.7) \mathrm{C}$ & $\mathrm{T} \times \mathrm{S} F_{4,194}=3.290$ & $\mathrm{~T} \times \mathrm{S}$ & $\mathrm{p}=0.01$ \\
\hline \multicolumn{7}{|c|}{ Mean ephyrae/(buds+ephyrae) $\times 100(\mathrm{SE})$} \\
\hline 20 & $7.7(5.3) \mathrm{a}$ & $11.5(4.3) \mathrm{a}$ & $63.3(5.9) \mathrm{C}$ & $\mathrm{T} F_{2,194}=82.700$ & $\mathrm{~T}$ & $p<0.001$ \\
\hline 27 & $12.1(5.2) \mathrm{a}$ & $49.7(6.4) \mathrm{b}$ & $64.4(6.8) \mathrm{C}$ & $\mathrm{S} F_{2,194}=6.369$ & $\mathrm{~S}$ & $\mathrm{p}=0.002$ \\
\hline 34 & $0(0)$ a & $47.3(6.6) \mathrm{b}$ & $73.0(7.6) \mathrm{C}$ & $\mathrm{T} \times \mathrm{S} F_{4,194}=4.878$ & $\mathrm{~T} \times \mathrm{S}$ & $\mathrm{p}<0.001$ \\
\hline
\end{tabular}




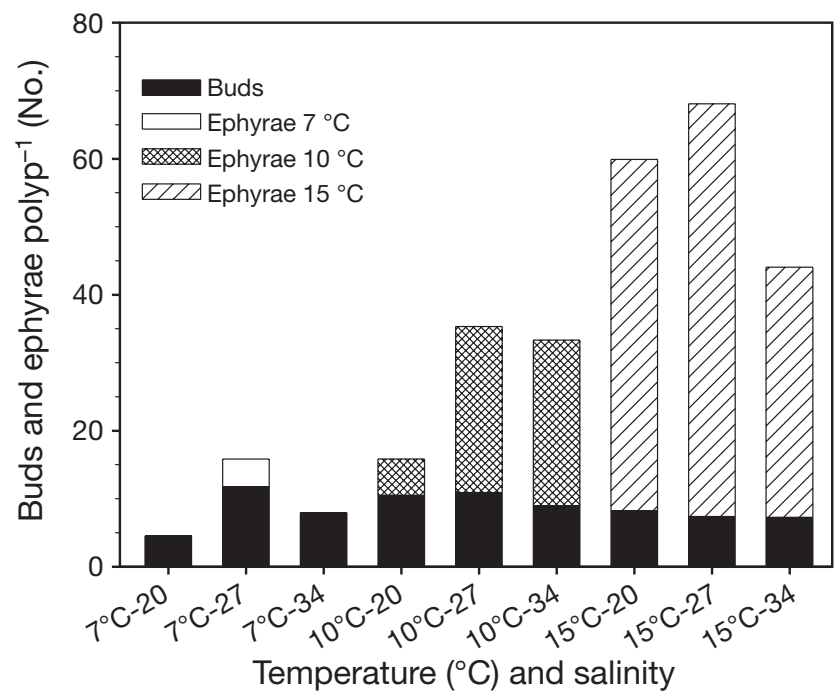

Fig. 1. Aurelia labiata. Numbers of buds and ephyrae produced per polyp (numbers of polyps in each treatment are given in Table 1) in a 142 d experiment (Expt 1) with 9 combinations of temperature $\left(7,10,15^{\circ} \mathrm{C}\right)$ and salinity $(20,27,34)$

number of times polyps strobilated (Table 1). Polyps in $7^{\circ} \mathrm{C}$ treatments strobilated only once, and only 1 polyp at $10^{\circ} \mathrm{C}-34$ strobilated twice; however, most polyps strobilated twice or even 3 times at $15^{\circ} \mathrm{C}$. Low salinity (20) reduced strobilation by polyps at $10^{\circ} \mathrm{C}$. The effect of temperature and the interaction of temperature and salinity were significant (both $\mathrm{p}<0.006$ ).

The numbers of ephyrae produced increased dramatically in warm temperatures (Table 1, Fig. 1). Only a few deformed ephyrae were produced in the $7^{\circ} \mathrm{C}$ treatments. More ephyrae were produced at $10^{\circ} \mathrm{C}$, and by far the most were produced at $15^{\circ} \mathrm{C}-27(41.7$ ephyrae polyp ${ }^{-1}$ ). Somewhat more ephyrae were produced at intermediate and high salinities (27 and 34) than at low salinity (7). The numbers of ephyrae differed among treatments, with temperature, salinity, and their interaction having significant effects (all p < 0.003).
The total numbers of ephyrae increased greatly with temperature while the numbers of buds decreased somewhat (Fig. 1). Thus, the proportion of ephyrae of the total asexual reproduction increased with temperature (Table 1). Bud production predominated (>78\%) in all $7^{\circ} \mathrm{C}$ treatments and $10^{\circ} \mathrm{C}-20$; bud and ephyra production were approximately equal at $10^{\circ} \mathrm{C}-27$ and $10^{\circ} \mathrm{C}-34$; and ephyra production predominated (63 to $73 \%$ ) in $15^{\circ} \mathrm{C}$ treatments. Low salinity (20) reduced the proportion of ephyrae somewhat. The proportions of ephyrae differed among treatments, with temperature, salinity, and their interaction having significant effects (all $\mathrm{p}<0.002$ ).

Expt 2 (116 d) tested the effect of high temperature $\left(20^{\circ} \mathrm{C}\right)$ that was well above the normal range of polyps ( 7 to $15^{\circ} \mathrm{C}$; Table 2 ). The results confirmed those of Expt 1 at temperatures that were repeated (10 and $15^{\circ} \mathrm{C}$ ), but no detrimental effects of high temperature were apparent. Survival was high in all treatments (83.3 to $100 \%$ ), and all except 1 polyp strobilated. Fewer buds were produced at $15^{\circ} \mathrm{C}$ than at $10^{\circ} \mathrm{C}$, and still fewer were produced at $20^{\circ} \mathrm{C}$. Strobilation was accelerated by increasing temperature $\left(10\right.$ and $\left.15^{\circ} \mathrm{C}\right)$, but no further increase was observed at $20^{\circ} \mathrm{C}$ (pairedcomparisons, Table 2). The number of strobilations poly $^{-1}$ increased at all temperatures $(\mathrm{p}<0.001)$. The total number of ephyrae polyp $\mathrm{p}^{-1}$ increased between 10 and $15^{\circ} \mathrm{C}$, but not between 15 and $20^{\circ} \mathrm{C}$. The percentage of ephyrae of the total asexual reproduction increased at all temperatures, reaching a mean of nearly $90 \%$ at $20^{\circ} \mathrm{C}(\mathrm{p}=<0.001)$. Thus, with increasing temperature, even at $5^{\circ} \mathrm{C}$ above the local high temperature, asexual production of jellyfish increased.

\section{Light intensity and duration experiment}

The effects of light exposure on asexual reproduction of Aurelia labiata polyps were tested in combinations of light duration $=$ photoperiod $\left(12,8\right.$, and $\left.4 \mathrm{~h} \mathrm{~d}^{-1}\right)$

Table 2. Aurelia labiata. Test of the effects of high temperature $\left(20^{\circ} \mathrm{C}\right)$ versus ambient temperatures $\left(10,15^{\circ} \mathrm{C}\right)$ on sexual reproduction for polyps during a $116 \mathrm{~d}$ experiment (Expt 2$)$. The initial number of polyps $(\mathrm{n})$ in each treatment was 18 . One-way ANOVAs $(F)$. $H$ : Kruskal-Wallis statistic. Significantly different pair-wise comparisons are indicated by different letters (a, b, c). NS: not significant

\begin{tabular}{|c|c|c|c|c|c|}
\hline & & \multirow{2}{*}{$\begin{array}{c}\text { Temperature } \\
15^{\circ} \mathrm{C}\end{array}$} & & \multirow{2}{*}{ Test statistic } & \multirow{2}{*}{$\mathrm{p}$ value } \\
\hline & $10^{\circ} \mathrm{C}$ & & $20^{\circ} \mathrm{C}$ & & \\
\hline No. of surviving polyps & 18 & 16 & 15 & $t_{2}=-1.890$ & NS \\
\hline No. of strobilating polyps & 12 & 16 & 13 & $t_{2}=-1.512$ & NS \\
\hline Mean no. of buds polyp ${ }^{-1}$ (SE) & $9.7(0.9)$ a & $7.1(0.6) \mathrm{b}$ & $3.9(0.5) \mathrm{C}$ & $F_{2,45}=15.536$ & $<0.001$ \\
\hline Mean no. of days to first strobilation (SE) & $65.6(5.3)$ a & $32.2(3.6) \mathrm{b}$ & $31.3(6.1) \mathrm{b}$ & $H_{2}=22.188$ & $<0.001$ \\
\hline Mean no. of strobilations polyp ${ }^{-1}(\mathrm{SE})$ & $1.1(0.1) \mathrm{a}$ & $1.5(0.1) \mathrm{ab}$ & $1.9(0.1) \mathrm{b}$ & $H_{2}=16.407$ & $<0.001$ \\
\hline Mean no. of ephyrae polyp ${ }^{-1}$ (SE) & $24.8(2.7) \mathrm{a}$ & $50.7(6.6) \mathrm{b}$ & $47.3(5.9) \mathrm{b}$ & $H_{2}=8.287$ & 0.003 \\
\hline Mean ephyrae/(ephyrae+buds) $\times 100(\mathrm{SE})$ & $74.8(2.8) \mathrm{a}$ & $85.5(1.9) \mathrm{ab}$ & $89.1(2.8) \mathrm{b}$ & $H_{2}=14.783$ & $<0.001$ \\
\hline
\end{tabular}


and light intensity (1 or 2 screens, or opaque black plastic) at local seawater temperature $\left(12^{\circ} \mathrm{C}\right)$ and salinity (27). Photoperiod in Puget Sound ranges from $8 \mathrm{~h}$ $\mathrm{d}^{-1}$ during winter to $16 \mathrm{~h} \mathrm{~d}^{-1}$ in summer. Light intensities in treatments with 1 screen (52 lux) and with 2 screens (26 lux) were similar to intensities underneath the dock where A. labiata polyps occur (Table 3). The daily amounts of light in the screened treatments (sum of Onset logger readings, Table 4) were similar to the daily totals under the dock (Table 3 ).

Survival of the initial polyps was very high (83.3 to $100 \%$ ) in the $201 \mathrm{~d}$ Expt 3, with no significant differences among treatments (Table 5, p > 0.05). Light exposure did not affect polyp survival. 'Deaths' were due to occasional losses during maintenance. Bud production in all treatments began immediately. The numbers of buds produced did not differ much among

Table 3. Light measurements using a a LiCor LI-193SA Spherical Quantum sensor, a ${ }^{\mathrm{b}}$ Biospherical Instrument QSL-100 light meter ( $\mu \mathrm{mol}$ photons $\mathrm{s}^{-1} \mathrm{~m}^{-2}$ ), and an ${ }^{\mathrm{c}}$ Onset light and temperature logger (lux $=$ lumens $\mathrm{m}^{-2}$ ) in Cornet Bay, Washington, where Aurelia labiata polyps occur under floats beneath a covered dock, and in laboratory incubators. Lux d ${ }^{-1}$ represents the daily sum of readings taken at 5 min intervals. ND: no data, $\mathrm{BD}$ : below detection limits of the light meters

\begin{tabular}{|c|c|c|c|c|}
\hline Location & $\begin{array}{l}\text { Quanta } \\
\mathrm{s}^{-1} \mathrm{~cm}^{-2}\end{array}$ & $\begin{array}{l}\text { ol photons } \\
\mathrm{s}^{-1} \mathrm{~m}^{-2}\end{array}$ & $\operatorname{Lux}^{\mathrm{c}}$ & $\begin{array}{l}\operatorname{Lux} \\
d^{-1 c}\end{array}$ \\
\hline $\begin{array}{l}\text { Cornet Bay, } \\
\text { Jan } 05\end{array}$ & ND & ND & $\leq 67$ & $2597 \pm 1160$ \\
\hline $\begin{array}{l}\text { Cornet Bay, } \\
25 \text { Mar } 04\end{array}$ & $1.2-1.8 \times 10^{14}$ & $2-3^{a}$ & $\leq 140$ & 6666 \\
\hline $\begin{array}{c}\text { Cornet Bay, } \\
17 \text { Jun } 04\end{array}$ & $1.8-3.6 \times 10^{14}$ & $3-6^{a}$ & $\leq 132$ & 2360 \\
\hline $\begin{array}{l}\text { Incubator-1 } \\
\text { screen }\end{array}$ & $0.285 \times 10^{14 b}$ & 0.47 & 52 & $7488(12 \mathrm{~h})$ \\
\hline $\begin{array}{l}\text { Incubator-2 } \\
\text { screens }\end{array}$ & $0.125 \times 10^{14 b}$ & 0.21 & 26 & $3744(12 \mathrm{~h})$ \\
\hline $\begin{array}{l}\text { Incubator- } \\
\text { opaque }\end{array}$ & $\mathrm{BD}$ & $\mathrm{BD}$ & $\mathrm{BD}$ & $\mathrm{BD}$ \\
\hline
\end{tabular}

Table 4. Relative light exposure in 6 combinations of photoperiod $\left(12,8,4 \mathrm{~h} \mathrm{~d}^{-1}\right)$ and light intensity (1 or 2 screens) in an experiment testing the effects of light on asexual reproduction by Aurelia labiata polyps (Expt 3). Instantaneous Onset light and temperature logger readings averaged 52 lux in all treatments. Lux d ${ }^{-1}$ values were calculated from 288 readings $\mathrm{d}^{-1}$, and assuming that the second screen halved the light

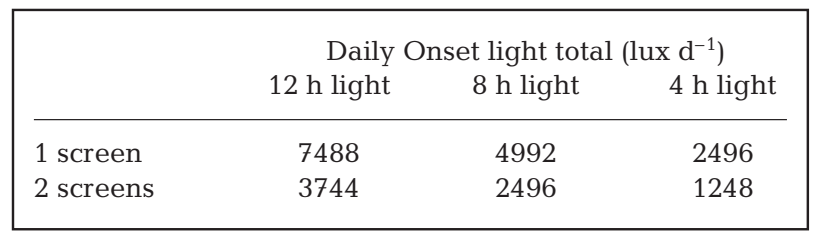

treatments, totaling about 30 buds polyp $^{-1}$ (Fig. 2, Table 6), and the differences were significant only for the interaction between photoperiod and light intensity $(\mathrm{p}<0.05)$. Somewhat fewer buds were produced in treatments with less light. Light exposure did not have a marked effect on bud production.

Prior to the experiment, the polyps were raised in a well-lit environment $\left(43715 \pm 12702\right.$ lux d $\left.^{-1}\right)$; therefore the first strobilation cycle was believed to be affected by light exposure. Nearly $100 \%$ of the polyps strobilated, and there were no significant differences among treatments (Table 5; p > 0.05). Strobilation success for the second strobilation $(77.8 \%)$ showed some reductions in the mid- and short-photoperiod treatments; however, differences among treatments were not significant (Table 5; p > 0.05). Markedly fewer polyps strobilated a third time $(7.2 \%)$, with the most strobilating in the greatest light exposure (12 h, 1 screen); differences among treatments were significantly different ( $p<0.001)$. Polyps receiving the most light strobilated more often than those in the other treatments.

The time until the second strobilation differed dramatically among treatments and was 20 to $40 \mathrm{~d}$ shorter (103 and $104 \mathrm{~d}$ ) in treatments with the longest photoperiod $(12 \mathrm{~h}$ ) with screens than in treatments with short photoperiods ( 8 and $4 \mathrm{~h}$ ) or in the dark (Fig. 3, Table 6. The effect of photoperiod was significant ( $p<0.001)$, as

Table 5. Aurelia labiata. Effect of light exposure on polyps tested in combinations of photoperiod $\left(12,8\right.$, and $\left.4 \mathrm{~h} \mathrm{~d}^{-1}\right)$ and light intensity ( 1 or 2 screens or opaque) at local seawater temperature $\left(12^{\circ} \mathrm{C}\right)$ and salinity $(27)$ in a $201 \mathrm{~d}$ experiment (Expt 3). Chi-squared tests showed that differences in survival and in strobilation were not significant among treatments, except for the numbers of polyps strobilating for a third time. NS: not significant

\begin{tabular}{|c|c|c|c|c|c|}
\hline & \multicolumn{5}{|c|}{ No. of strobilating polyps/No. of surviving polyps } \\
\hline & $\begin{array}{l}12 \mathrm{~h} \\
\text { light }\end{array}$ & $\begin{array}{c}8 \mathrm{~h} \\
\text { light }\end{array}$ & $\begin{array}{l}4 \mathrm{~h} \\
\text { light }\end{array}$ & $\begin{array}{c}\text { Test } \\
\text { statistic }\end{array}$ & $\begin{array}{c}\mathrm{p} \\
\text { value }\end{array}$ \\
\hline \multicolumn{6}{|c|}{ First strobilation } \\
\hline 1 screen & $18 / 18$ & $18 / 18$ & $17 / 17$ & \multirow[t]{3}{*}{$\begin{array}{c}\chi_{4}^{2}=0.143 / \\
\chi^{2}{ }_{4}=0.143\end{array}$} & \multirow[t]{3}{*}{ NS/NS } \\
\hline 2 screens & $18 / 18$ & $17 / 18$ & $18 / 18$ & & \\
\hline Opaque & $18 / 18$ & $16 / 16$ & $17 / 18$ & & \\
\hline \multicolumn{6}{|c|}{ Second strobilation } \\
\hline 1 screen & $14 / 18$ & $13 / 17$ & $14 / 17$ & \multirow[t]{3}{*}{$\begin{array}{c}\chi_{4}^{2}=1.272 / \\
\chi_{4}^{2}=0.318\end{array}$} & \multirow[t]{3}{*}{ NS/NS } \\
\hline 2 screens & $14 / 16$ & $12 / 17$ & $14 / 17$ & & \\
\hline Opaque & $15 / 18$ & $8 / 15$ & $15 / 18$ & & \\
\hline \multicolumn{6}{|c|}{ Third strobilation } \\
\hline 1 screen & $5 / 18$ & $0 / 17$ & $1 / 17$ & \multirow[t]{3}{*}{$\begin{array}{c}\chi_{4}^{2}=26.527 / \\
\chi^{2}{ }_{4}=0.318\end{array}$} & \multirow[t]{3}{*}{$<0.001 / \mathrm{NS}$} \\
\hline 2 screens & $1 / 16$ & $0 / 17$ & $0 / 17$ & & \\
\hline Opaque & $1 / 18$ & $1 / 15$ & $2 / 18$ & & \\
\hline
\end{tabular}




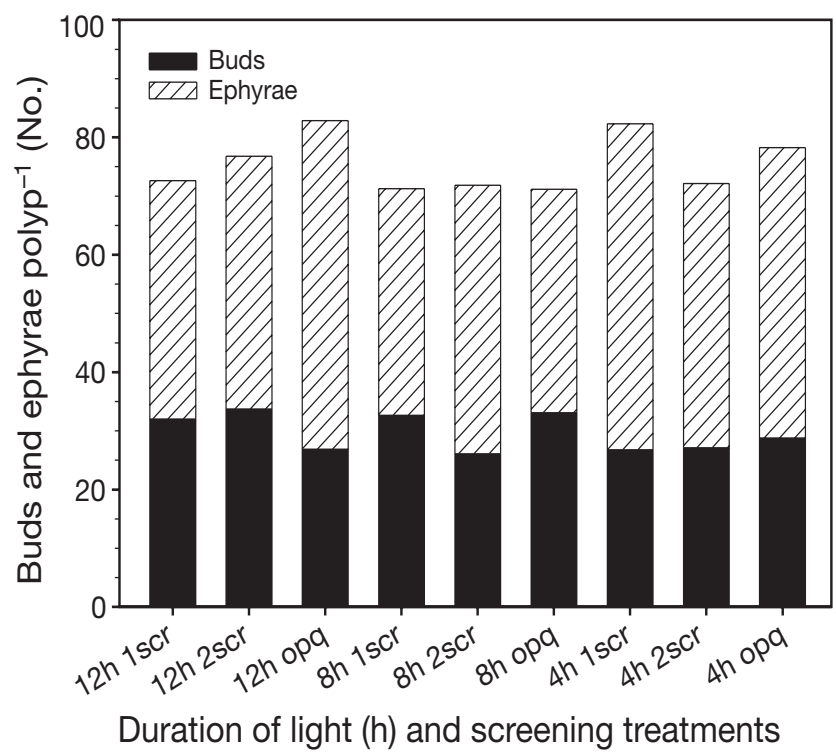

Fig. 2. Aurelia labiata. Effect of light exposure on the total numbers of buds and ephyrae produced by polyps over $201 \mathrm{~d}$ (Expt 3) in combinations of photoperiod $\left(12,8\right.$, and $\left.4 \mathrm{~h} \mathrm{~d}^{-1}\right)$ and light intensity (1 or 2 screens [scr] or opaque [opq]) at local seawater temperature $\left(12^{\circ} \mathrm{C}\right)$ and salinity $(27)$. The numbers of polyps are given in Table 5 was the interaction between photoperiod and light intensity $(\mathrm{p}<0.001)$. Thus, greater light exposure accelerated strobilation.

More ephyrae were produced in the short-day treatments (means 52 to 60 polyp $^{-1}$ ) than in the long-day treatments (means 42 to 63 polyp $^{-1}$; Table 6). Among the $12 \mathrm{~h}$ light treatments, more ephyrae (mean 63 poly $^{-1}$ ) were produced in the opaque treatment than in the other light intensity treatments $\left(44\right.$ polyp $\left.^{-1}\right)$. The differences were significant among photoperiod treatments $(\mathrm{p}<0.05 ;$ Table 6$)$. Thus, more ephyrae were produced in treatments with low light where they took many days to strobilate. The percentages of ephyrae of the total asexual reproduction showed a similar pattern to the number of ephyrae polyp ${ }^{-1}$, with somewhat greater percentages in low light; however, the differences among treatments were not significant.

\section{DISCUSSION}

\section{Temperature effects on asexual reproduction}

All measures of Aurelia labiata ephyra production showed that more ephyrae were produced with in-

Table 6. Aurelia labiata. Effect of light exposure on asexual reproduction by polyps tested in combinations of photoperiod (P; 12,8 , and $4 \mathrm{~h} \mathrm{~d}^{-1}$ ) and light intensity ( $\mathrm{I}_{;} 1$ or 2 screens or opaque) at local seawater temperature $\left(12^{\circ} \mathrm{C}\right)$ and salinity $(27)$ in a $201 \mathrm{~d}$ experiment (Expt 3). The number of polyps in each treatment is given in Table 5. Two-way ANOVAs showed significant effects $(F)$. $H$ : Kruskal-Wallis statistic. Significantly different pair-wise comparisons for each ANOVA are indicated by different letters (a, b, c)

\begin{tabular}{|c|c|c|c|c|c|}
\hline \multirow[t]{2}{*}{ Light intensity } & \multicolumn{5}{|c|}{ Photoperiod } \\
\hline & $12 \mathrm{~h}$ light $\mathrm{d}^{-1}$ & 8 h light d ${ }^{-1}$ & $4 \mathrm{~h}$ light $\mathrm{d}^{-1}$ & Test statistic & $\mathrm{p}$ value \\
\hline \multicolumn{6}{|c|}{ Mean no. of buds polyp ${ }^{-1}$ (SE) } \\
\hline 1 screen & $32.0(1.9)$ & $32.2(2.1)$ & $26.8(2.1)$ & $\mathrm{P} \quad F_{2,144}=2.068$ & $\mathrm{P}$ NS \\
\hline 2 screens & $33.7(2.2)$ & $26.1(1.7)$ & $27.1(2.0)$ & I $F_{2,144}=0.301$ & I NS \\
\hline Opaque & $26.8(1.8)$ & $33.1(3.2)$ & $28.8(2.4)$ & $\mathrm{P} \times \mathrm{I} \quad F_{2,144}=2.791$ & $\mathrm{P} \times \mathrm{I} \mathrm{p}<0.05$ \\
\hline \multicolumn{6}{|c|}{ Mean no. of days until second strobilation $(\mathrm{SE})^{*}$} \\
\hline 1 screen & $103.2(8.4)$ a & $146.0(5.5) \mathrm{b}$ & $127.6(8.0) \mathrm{b}$ & $\mathrm{P} \quad F_{2,144}=7.774$ & $\mathrm{P} p<0.001$ \\
\hline 2 screens & $104.6(8.9)$ a & $132.2(7.4) \mathrm{b}$ & $129.9(5.2) \mathrm{b}$ & I $F_{2,144}=1.096$ & I NS \\
\hline Opaque & $134.1(4.0) \mathrm{b}$ & $123.7(9.4) \mathrm{b}$ & $130.2(6.2) \mathrm{b}$ & $\mathrm{P} \times \mathrm{I} \quad F_{2,144}=3.305$ & $\mathrm{P} \times \mathrm{I} \mathrm{p}=0.01$ \\
\hline \multicolumn{6}{|c|}{ Mean no. of strobilations polyp ${ }^{-1}$ (SE) } \\
\hline 1 screen & $2.1(0.2) \mathrm{a}$ & $1.8(0.1) \mathrm{b}$ & $2.0(0.1) \mathrm{ab}$ & $\mathrm{P} \quad F_{2,144}=3.820$ & $\mathrm{P} p<0.05$ \\
\hline 2 screens & $1.9(0.1)$ a & $1.6(0.2) \mathrm{b}$ & $1.8(0.1) \mathrm{ab}$ & I $F_{2,144}=1.131$ & I NS \\
\hline Opaque & $1.9(0.1) \mathrm{a}$ & $1.5(0.1) \mathrm{b}$ & $1.9(0.2) \mathrm{ab}$ & $\mathrm{P} \times \mathrm{I} \quad F_{2,144}=0.059$ & $\mathrm{P} \times \mathrm{I} \mathrm{NS}$ \\
\hline \multicolumn{6}{|c|}{ Mean no. of ephyrae polyp ${ }^{-1}$ (SE) } \\
\hline 1 screen & $44.6(3.7)$ a & $41.6(3.1)$ a & $59.7(4.9) \mathrm{b}$ & $\mathrm{P} \quad F_{2,144}=3.648$ & $\mathrm{P} p<0.05$ \\
\hline 2 screens & $44.0(4.3) \mathrm{a}$ & $55.2(3.1) \mathrm{b}$ & $52.1(3.5) \mathrm{ab}$ & I $F_{2,144}=1.005$ & I NS \\
\hline Opaque & $63.3(5.1) \mathrm{b}$ & $41.8(6.0) \mathrm{c}$ & $57.6(4.5) \mathrm{ab}$ & $\mathrm{P} \times \mathrm{I} \quad F_{2,144}=4.433$ & $\mathrm{P} \times \mathrm{I} p=0.002$ \\
\hline \multicolumn{6}{|c|}{ Mean ephyrae/(buds+ephyrae) $\times 100(\mathrm{SE})$} \\
\hline 1 screen & $54.4(2.9)$ & $53.4(2.9)$ & $64.8(3.9)$ & $\mathrm{P} \quad F_{2,144}=1.504$ & P NS \\
\hline 2 screens & $54.2(3.4)$ & $60.1(5.0)$ & $58.9(4.3)$ & I $F_{2,144}=0.012$ & I NS \\
\hline Opaque & $63.8(4.2)$ & $51.4(4.8)$ & $59.0(5.5)$ & $\mathrm{P} \times \mathrm{I} \quad F_{2,144}=1.750$ & $\mathrm{P} \times \mathrm{I} \quad \mathrm{NS}$ \\
\hline
\end{tabular}




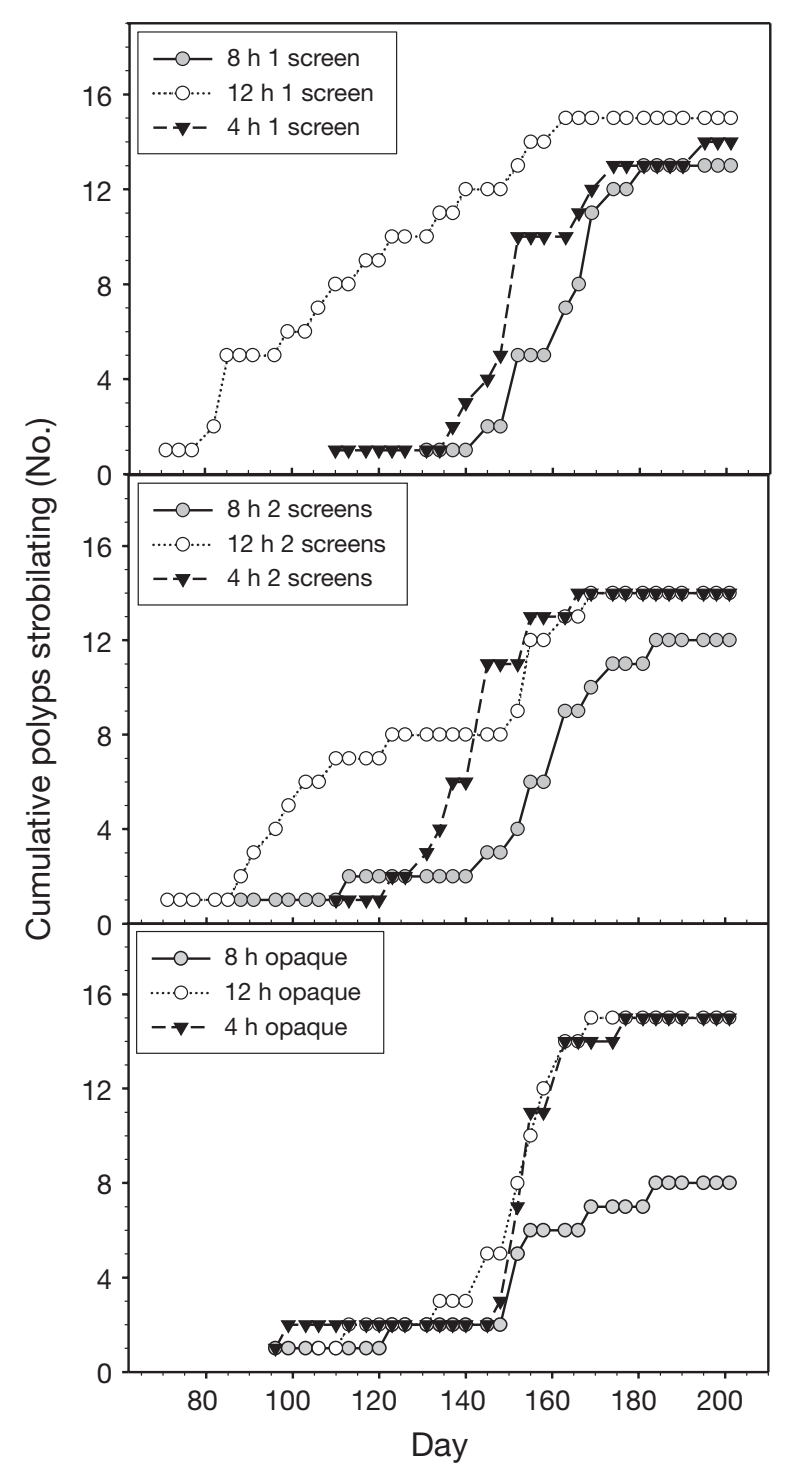

Fig. 3. Aurelia labiata. Cumulative numbers of strobilating polyps (second strobilation) in Expt 3 treatments combining photoperiod $\left(12,8\right.$, and $4 \mathrm{~h} \mathrm{~d}^{-1}$ ) and light intensity (1 or 2 screens or opaque) at local seawater temperature $\left(12^{\circ} \mathrm{C}\right)$ and salinity (27). Polyps in $12 \mathrm{~h}$ light strobilated much earlier than those in other treatments (see Table 6). Food was unavailable to the polyps on Days 134 and 137, and strobilation in the low-light treatments began soon thereafter. The numbers of polyps are given in Table 5

creasing temperature: greater percentages of polyps strobilated, strobilation occurred more quickly, more strobilation cycles occurred, each polyp released more ephyrae, and the proportions of ephyrae relative to buds increased. Even though local A. labiata polyps strobilate immediately following the seasonal low temperatures $\left(7^{\circ} \mathrm{C} ; \mathrm{J}\right.$. Purcell et al. unpubl.), ephyra production continued to increase to the highest temperature tested $\left(20^{\circ} \mathrm{C}\right)$. A. labiata occurs from central
California to Alaska. Its distribution and these results demonstrate a broad temperature tolerance. Each population is probably adapted to local conditions; thus, California polyps would be expected to respond differently than Washington or Alaska polyps (E. Ninmann \& J. Purcell unpubl.). Growth rates of A. labiata ephyrae from Monterey Bay, California, were maximum at $21^{\circ} \mathrm{C}$ (range tested: 8 to $28^{\circ} \mathrm{C}$; Widmer 2005).

Results from similar experiments on other species show the same trends as for Aurelia labiata; specifically, in warmer temperatures, more jellyfish are produced more rapidly, and the ratio of jellyfish to buds increases (Purcell et al. 1999, Ma \& Purcell 2005). The numbers of new jellyfish produced in all salinity treatments were summed for each temperature and plotted against temperature (Fig. 4A). The slopes of the lines indicate the strength of the response of each species to warming (Table 7). Two species from Chesapeake Bay, Maryland, USA, begin to produce jellyfish in the spring as temperatures warm above $15^{\circ} \mathrm{C}$; for each $1^{\circ} \mathrm{C}$ warming, Chrysaora quinquecirrha polyps increased ephyra production by 5.3 to $18.4 \%$; for each $1{ }^{\circ} \mathrm{C}$ warm-
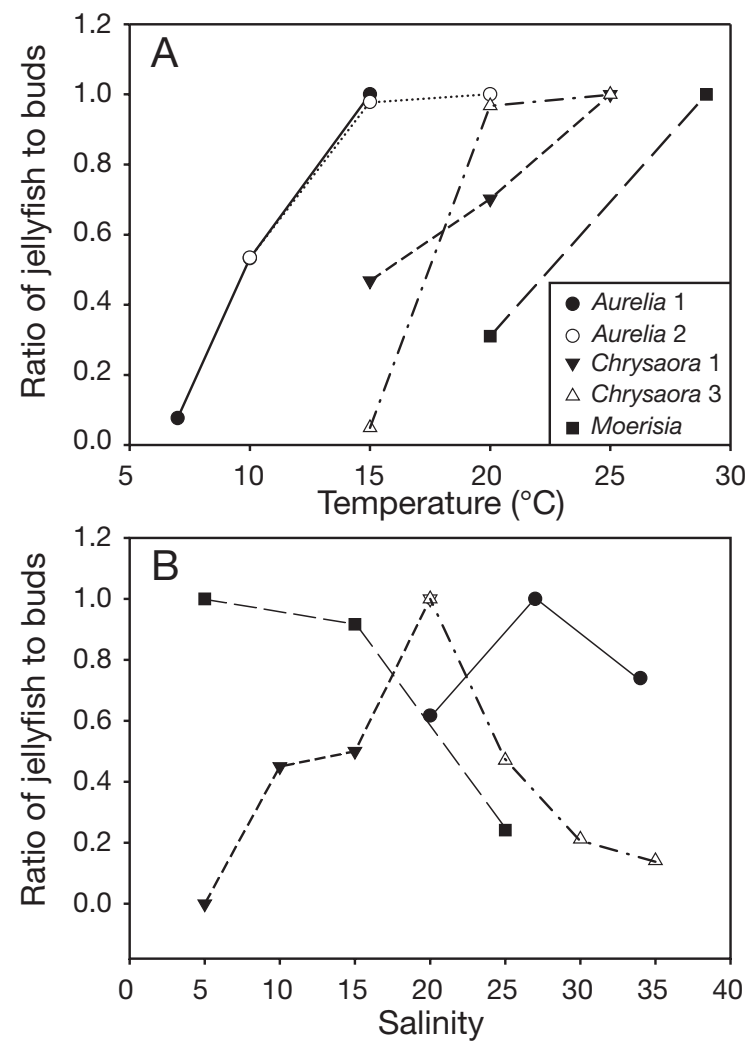

Fig. 4. Aurelia labiata, Chrysaora quinquecirrha, and Moerisia lyonsi. Ratios of new jellyfish to buds produced by polyps versus temperature (A) and versus salinity (B) for A. labiata (this study, Expts 1 \& 2), C. quinquecirrha (from Purcell et al. 1999, Expts 1 \& 3), and M. lyonsi (from Ma \& Purcell 2005). Numbers of A. labiata polyps in each treatment are given in Table 1 
Table 7. Aurelia labiata, Chrysaora quinquecirrha, and Moerisia lyonsi. Percentage increases in the number of jellyfish produced and the numbers of days production would be accelerated per $1{ }^{\circ} \mathrm{C}$ temperature increase and per salinity unit increase. These rates are the slopes of the lines in Figs. $4 \& 5$. The salinity or temperature range is given in brackets for each experiment

\begin{tabular}{|c|c|c|c|c|}
\hline Species and experiment & $\begin{array}{l}\text { Range tested } \\
\qquad\left({ }^{\circ} \mathrm{C}\right)\end{array}$ & $\begin{array}{l}\text { Increase in jellyfish } \\
\left(\% \text { per } 1^{\circ} \mathrm{C}\right)\end{array}$ & $\begin{array}{l}\text { Acceleration in jellyfish } \\
\text { production }\left(\mathrm{d} \text { per } 1^{\circ} \mathrm{C}\right)\end{array}$ & Source \\
\hline \multicolumn{5}{|l|}{ Temperature } \\
\hline Aurelia labiata [20-34] & $7-15$ & 11.3 & 4.24 & This study \\
\hline A. labiata $[27]$ & $10-15$ & 8.8 & 6.57 & This study \\
\hline A. labiata [27] & $15-20$ & 0.4 & 0.30 & This study \\
\hline Chrysaora quinquecirrha [5-20] & $15-25$ & 5.3 & 1.40 & Purcell et al. (1999) \\
\hline C. quinquecirrha [20-35] & $15-20$ & 18.4 & 1.40 & Purcell et al. (1999) \\
\hline C. quinquecirrha [20-35] & $20-25$ & 0.7 & 1.40 & Purcell et al. (1999) \\
\hline Moerisia lyonsi [5-25] & $20-29$ & 24.4 & 1.15 & Ma \& Purcell (2005) \\
\hline Salinity & (salinity units) & (\% per salinity unit) & (d per salinity unit) & \\
\hline A. labiata $\left[7-15^{\circ} \mathrm{C}\right]$ & $20-27$ & 3.2 & 1.95 & This study \\
\hline A. labiata $\left[7-15^{\circ} \mathrm{C}\right]$ & $34-27$ & 3.7 & 0.81 & This study \\
\hline C. quinquecirrha $\left[15-25^{\circ} \mathrm{C}\right]$ & $5-20$ & 6.7 & NA & Purcell et al. (1999) \\
\hline C. quinquecirrha $\left[15-20^{\circ} \mathrm{C}\right]$ & $35-20$ & 5.7 & NA & Purcell et al. (1999) \\
\hline M. lyonsi $\left[20-29^{\circ} \mathrm{C}\right]$ & $15-5$ & 0.7 & 0.08 & Ma \& Purcell (2005) \\
\hline M. lyonsi $\left[20-29^{\circ} \mathrm{C}\right]$ & $25-15$ & 28.2 & 0.82 & Ma \& Purcell (2005) \\
\hline
\end{tabular}

ing, Moerisia lyonsi polyps increased jellyfish production by $7.7 \%$ (Table 7). In Puget Sound, A. labiata polyps strobilate in early spring when temperatures are about $7^{\circ} \mathrm{C}$ (J. Purcell et al. unpubl). Their polyps increased ephyra production by 8.8 to $11.3 \%$ for each $1^{\circ} \mathrm{C}$ warming between 7 and $15^{\circ} \mathrm{C}$; above $15^{\circ} \mathrm{C}$, the increase was only $0.4 \%$.

Similarly, the number of days until jellyfish production in all salinity treatments were summed for each temperature and plotted against temperature (Fig. 5). The acceleration effect of temperature was less for both warm-water Chesapeake Bay species than for cool-water Aurelia labiata. Each $1^{\circ} \mathrm{C}$ warming accelerated jellyfish production by $1.4 \mathrm{~d}$ and $1.2 \mathrm{~d}$ for Chrysaora quinquecirrha and Moerisia lyonsi, respectively, but by 4.2 to $6.6 \mathrm{~d}$ for A. labiata at 7 to $15^{\circ} \mathrm{C}$; above $15^{\circ} \mathrm{C}$, the increase was only $0.3 \%$ (Table 7 ). Thus, A. labiata had a very strong response to warming from 7 to $15^{\circ} \mathrm{C}$, both in the ratio of ephyrae and in the acceleration of strobilation; however, little additional increase occurred at higher temperature $\left(15\right.$ to $\left.20^{\circ} \mathrm{C}\right)$.

Warming ocean temperatures may have several positive effects on jellyfish populations. (1) Both long-term population correlations and experimental data show increased jellyfish populations in warm conditions (reviewed by Purcell 2005). Climate models project that global warming due to human influences will be 0.1 to $0.2^{\circ} \mathrm{C}$ per decade, and that ocean surface temperatures will rise nearly everywhere (Alley et al. 2007). Thus, warmer ocean temperatures may increase the numbers of jellyfish in the future (Attrill et al. 2007). (2) Warm temperatures also accelerate production of jellyfish. Disappearance of temperate jellyfish in the winter is associated with cold temperatures, although some populations overwinter. Therefore, warming may cause jellyfish to appear earlier, persist longer, and perhaps even survive through the winter. (3) Jellyfish distributions may broaden or shift as a result of temperature changes. For example, low $\left(<4^{\circ} \mathrm{C}\right)$ winter temperatures apparently limit the distribution of Mnemiopsis leidyi ctenophores (reviewed by Purcell et al. 2001). Faasse \& Bayha (2006) speculated that the invasion of $M$. leidyi in the North Sea occurred during recent unusually high temperatures. The greater production of dispersive jellyfish relative to

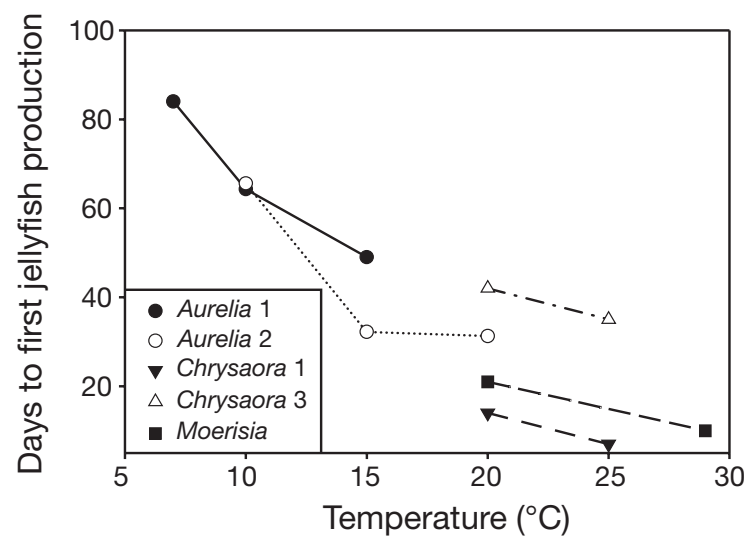

Fig. 5. Aurelia labiata, Chrysaora quinquecirrha, and Moerisia lyonsi. Numbers of days until new jellyfish were produced by polyps of $A$. labiata (this study, Expt $1: 7$ to $15^{\circ} \mathrm{C}$ and salinity 20, Expt 2: 10 to $20^{\circ} \mathrm{C}$ and salinity 27), C. quinquecirrha (Expts 1 \& 3 from Purcell et al. 1999), and M. lyonsi (from Ma \& Purcell 2005) versus temperature. Numbers of A. labiata polyps in each treatment are given in Table 1 
attached polyps could promote range expansion. In summary, ocean warming may increase the population sizes of gelatinous species, lengthen their seasons, and increase their distributions. By contrast, species living near their upper thermal tolerance presumably would not be positively affected by warming.

\section{Salinity effects on asexual reproduction}

The effects of salinity on asexual reproduction by $A u$ relia labiata polyps were significant, but less dramatic than those of temperature. The salinity differences tested among treatments were extreme changes (7) probably not experienced for extended periods by the polyps in nature. Week-long heavy rains reduced salinity to as low as 17 in the shallow Cornet Bay marina, Washington, where A. labiata polyps thrive; salinity there routinely varies between 24 and 28 (J. Purcell et al. unpubl. data). Salinity effects on feeding and growth rates of $A$. aurita ephyrae with unlimited food were significant, with the greatest rates at the highest (ambient) salinity (range tested 17.5 to 35; Båmstedt et al. 1999).

Jellyfish production by Aurelia labiata polyps from Puget Sound was compared to that of Chrysaora quinquecirrha and Moerisia lyonsi polyps from the mesohaline Chesapeake Bay (Table 7). The numbers of jellyfish produced in all temperature treatments were summed for each salinity and plotted against salinity (Fig. 4B). For each salinity unit different from their optimum (20), ephyra production of C. quinquecirrha changed by 5.7 to $6.7 \%$. Jellyfish production by M. lyonsi polyps increased by $13.5 \%$ per salinity unit decrease from high salinities, but only by $1.7 \%$ per salinity unit decrease at low salinities (optimum 5). A. labiata ephyra production changed by 3.7 to $5.5 \%$ per salinity unit from their optimum (27).

Increased jellyfish populations in semi-enclosed bodies of water have been attributed to changes in salinity that are due to climate variations as well as human perturbations. Chrysaora quinquecirrha jellyfish in Chesapeake Bay (Cargo \& King 1990, Purcell et al. 1999) and Pelagia noctiluca (Goy et al. 1989) and other species (Molinero et al. 2005) in the Mediterranean Sea are abundant in years with high salinity. Modifications of freshwater inflow have also been associated with jellyfish blooms (e.g. Xian et al. 2005). Observed consequences of global warming include changed rainfall over large regions, melting of glaciers and pack ice, and earlier seasonal melting of snow pack; these changes are predicted to continue (Alley et al. 2007), and will alter the salinity regimes, especially in estuaries and coastal waters where populations of jellyfish may be especially affected by and responsive to salinity changes.

\section{Combined effects of temperature and salinity}

Interactions of temperature and salinity were significant for all measures of asexual reproduction in Aurelia labiata (Table 1). For example, the combination of high salinity $(34)$ and low temperature $\left(7^{\circ} \mathrm{C}\right)$ reduced survival and budding, and polyps did not strobilate (Table 1). In nature, high temperatures with high salinity are related to large populations of some gelatinous species (Goy et al. 1989, Raskoff 2001, Xian et al. 2005). By contrast, severe reduction of Mastigias sp. in a tropical marine lake coincided with high temperature and salinity conditions of an El Niño (Dawson et al. 2001).

To develop a predictive capability for temperature (T) and salinity (S) effects on jellyfish populations, I used multiple regression analyses for Aurelia labiata and Moerisia lyonsi (original data for Chrysaora quinquecirrha were unavailable). The regression analysis for the number of days to ephyra production by A. labiata $\left(\mathrm{D}_{\mathrm{A}}\right)$ was significant $\left(\mathrm{ANOVA}, F_{2,107}=44.90, \mathrm{p}<\right.$ $\left.0.001, \mathrm{r}^{2}=0.456\right)$, and the constant $(t=14.56)$, temperature $(t=-9.03)$, and salinity $(t=-2.92)$ were all significant $(\mathrm{p}<0.004) . \mathrm{D}_{\mathrm{A}}$ can be predicted from the equation $\mathrm{D}_{\mathrm{A}}=111.51-3.55(\mathrm{~T})-0.63(\mathrm{~S})$. Thus, temperature and salinity explained $46 \%$ of the variation in timing of jellyfish production. The regression analysis for the number of ephyrae produced by $A$. labiata $\left(\mathrm{E}_{\mathrm{A}}\right)$ was also significant (ANOVA, $F_{2,200}=76.52, \mathrm{p}<0.001, \mathrm{r}^{2}=$ $0.433)$; the constant $(t=-5.04)$ and temperature $(t=$ $12.37)$ were significant $(\mathrm{p}<0.001) . \mathrm{E}_{\mathrm{A}}$ can be predicted from the equation $\mathrm{E}_{\mathrm{A}}=-67.17+8.59(\mathrm{~T})+0.17(\mathrm{~S})$. Temperature and salinity explained $43 \%$ of the number of jellyfish produced, and temperature was more important than salinity.

The regression analysis for the number of days to jellyfish production by $M$. lyonsi $\left(\mathrm{D}_{\mathrm{M}}\right)$ was significant (ANOVA, $F_{2,66}=116.41, \mathrm{p}<0.001, \mathrm{r}^{2}=0.779$ ), and the constant ( $t=14.85)$, temperature $(t=-13.03)$, and salinity $(t=8.65)$ were all significant $(\mathrm{p}<0.001)$. $\mathrm{D}_{\mathrm{M}}$ can be predicted from the equation $\mathrm{D}_{\mathrm{M}}=35.35+0.44(\mathrm{~S})-$ $1.20(\mathrm{~T})$. Thus, temperature and salinity explained $78 \%$ of the variation in timing of jellyfish production, and temperature had a stronger effect than salinity. The regression analysis for the number of jellyfish produced by $M$. lyonsi $\left(\mathrm{M}_{\mathrm{M}}\right)$ was also significant (ANOVA, $\left.F_{2,69}=15.10, \mathrm{p}<0.001, \mathrm{r}^{2}=0.304\right)$; only temperature $(t$ $=4.26)$ was significant $(\mathrm{p}<0.001) . \mathrm{M}_{\mathrm{M}}$ can be predicted from the equation $\mathrm{M}_{\mathrm{M}}=-28.80+3.13(\mathrm{~T})-1.40(\mathrm{~S})$. Temperature explained only $30 \%$ of the number of jellyfish produced. Food consumption was previously shown to be the most important factor in reproduction rate and ratio of jellyfish to polyp production, while temperature and salinity were most important for the time of jellyfish release (Ma \& Purcell 2005). 
The preceding estimates of changes in the numbers and timing of jellyfish production relative to temperature and salinity may not be applicable in nature. First, the experimental polyps were provided with much more food than available in situ. Second, differences among the treatments were more extreme $\left(3\right.$ to $9^{\circ} \mathrm{C}$ and 5 to 7 salinity) than interannual variation in nature. Many factors (temperature, salinity, light, and prey abundance) change before jellyfish production in spring or autumn. Environmental changes in situ are more subtle, more gradual, and occur non-synchronously. Therefore, the responses of polyps in situ would not be as dramatic as observed in these experiments.

Estuarine cnidarian and ctenophore species appear to be eurythermal and euryhaline, thriving over wide ranges of conditions (e.g. Purcell et al. 1999, 2001, Ma $\&$ Purcell 2005). Cnidarians also have very versatile reproductive strategies (Lucas 2001, Boero et al. 2002). This versatility may predispose them to exploit changing conditions that may prove detrimental to other species. Such adaptability of Mnemiopsis leidyi has enabled this ctenophore species to invade and dominate the plankton food web in the Black, Asov, and Caspian Seas (e.g. Finenko et al. 2006), and now to invade the North and Baltic Seas (Faasse \& Bayha 2006). Gelatinous species may respond favorably to the many environmental changes occurring in coastal waters.

\section{Effects of light on strobilation}

The strongest effect of light on asexual reproduction by Aurelia labiata polyps was on the time to strobilation. Photoperiod $(\mathrm{p}<0.001)$ and its interaction with light intensity $(\mathrm{p}<0.01)$ were significant factors; polyps that received the most light (12 h, 1 screen) strobilated more quickly than those in any other treatment, and polyps strobilated more times in that treatment than in any other. The fact that the most rapid strobilation occurred in both 1- and 2-screen treatments in $12 \mathrm{~h}$ light suggests that photoperiod is most important, rather than the total amount of light received (Table 4).

Polyps in the $8 \mathrm{~h}$ and $4 \mathrm{~h}$ light treatments began to strobilate immediately after the disappearance of food (Fig. 3, Table 6). The absence of food may have triggered strobilation in low-light treatments before it otherwise would have occurred. Starvation has been suggested as a trigger for strobilation (Arai 1997, Ishii \& Watanabe 2003), and strobilation occurs in situ after zooplankton is at the seasonal low.

A possible error in Expt 3 could have occurred if temperatures differed among treatments. The effects of the different light intensity treatments (1 or 2 screens or black plastic) on temperature were tested by the Onset data loggers in $12 \mathrm{~h}$ light. Temperature differed slightly among the light intensity treatments, being slightly warmer with increased cover (Table 8). This result strengthens the conclusion of the light experiment, i.e. that strobilation occurred more rapidly in higher-light treatments, which is the opposite of the expected results if warm temperature had been a determining factor in this experiment.

Photoperiod also significantly affected the number of ephyrae polyp ${ }^{-1}$, and the interaction of photoperiod with light intensity was significant for the number of buds polyp ${ }^{-1}$ (both $\mathrm{p}<0.05$ ). The polyps in treatments producing more ephyrae strobilated later than in other treatments, and therefore, they fed for a longer time. It is probable that the additional food enabled them to produce more ephyrae polyp ${ }^{-1}$. The treatments with more ephyrae had fewer buds, as in the T-S experiments, suggesting that the additional food energy in low-light treatments was allocated to ephyra production rather than budding. Abundant food increased production of jellyfish relative to buds in other species (Purcell et al. 1999, Ma \& Purcell 2005). Therefore, the observed differences in ephyra and bud production probably were related to food consumption; however, a direct effect of light cannot be ruled out.

\section{Importance of light in seasonal cycles}

Coordination of reproduction with daily light cycles and with the seasonal cycle of production is common in terrestrial and aquatic ecosystems. Among prokaryotes, protozoans, plants, invertebrates, and vertebrates, mechanisms to respond to light cycles (daily or seasonal, lunar or solar) are common if not universal in photic environments (Leitz 2001). Light-sensitive asexual and sexual reproduction has been observed for many marine invertebrates, for example, among scyphozoans and hydrozoans (Spangenberg 1968, Loeb 1973, Honegger et al. 1980, Genzano \& Kubota 2003). It is obviously important for Aurelia labiata

Table 8. Effects of light intensity on temperature in treatments testing light effects on asexual reproduction of Aurelia labiata polyps (Expt 3). Results are shown for a $12 \mathrm{~h}$ photoperiod. Temperatures were recorded every $5 \mathrm{~min}$ with an Onset light and temperature logger. Means \pm SE are given for a $2 \mathrm{wk}$ period

\begin{tabular}{|cc|}
\hline Light intensity & Temperature $\left({ }^{\circ} \mathrm{C}\right)$ \\
\hline 1 screen & $10.30 \pm 0.13$ \\
2 screens & $10.95 \pm 0.04$ \\
Opaque & $11.08 \pm 0.03$ \\
\hline
\end{tabular}


polyps to produce ephyrae when their small planktonic prey are abundant.

Light plays a critical role in hormonal changes for plants and animals (e.g. Boeuf \& Falcon 2001, Farnsworth 2004). Melatonin regulates circadian rhythms and photoperiodism throughout the animal kingdom from protozoans to mammals (reviewed by Hardeland 1997, Pandi-Perumal et al. 2006). In many animals, light and temperature interact to regulate melatonin (Balzer \& Hardeland 1996). The endocrinology of marine invertebrates has been studied much less than that of terrestrial organisms (Leitz 2001); nevertheless, a few examples of hormone-like activities exist for cnidarians. Aurelia aurita polyps require iodine and synthesize thyroxin during strobilation (reviewed by Spangenberg 1977); subsequently, iodine was shown to function in statocyst formation in the developing ephyrae (Spangenberg 1984). Melatonin showed a seasonal cycle in the one cnidarian examined, the sea pansy Renilla renilla (Mechawar \& Anctil 1997). Therefore, I believe it is probable that melatonin, or a precursor like serotonin, may be synthesized in proportion to light exposure in A. labiata polyps, and coordinates the timing of strobilation seasonally. Because light also affects other species, I suspect that light-sensitive hormonal regulation of behavioral and reproductive cycles is common among scyphozoans and other cnidarians.

\section{Global changes in Earth's light regime and possible effects on jellyfish populations}

The amount of sunlight that reaches the Earth's surface is changing due to the effects of human activities. Changes in warming and in the amount of surface sunlight (insolation) are due to changes in the amounts and proportions of light-reflecting and light-absorbing greenhouse gasses (GHG; water vapor, $\mathrm{CO}_{2}, \mathrm{CH}_{4}$, ozone, $\mathrm{NO}_{2}$ ) and aerosols from natural (e.g. sea salt and soil dust) and anthropogenic (e.g. soot) sources and cloud formation in the atmosphere (Butchart et al. 2000, Pallé \& Butler 2002, Satheesh \& Krishna Moorthy 2005). For a century prior to the 1990 s, cloud cover was increasing and light diminishing (Pallé \& Butler 2002); however, this long-term trend seems to have reversed recently (Wild et al. 2005). Because warming and human perturbations are increasing, it is likely that cloud cover and temperatures will increase, but that insolation will decrease in the future (Pallé \& Butler 2002); however, because of the great complexity of the many interacting factors, uncertainty in predicting cloud cover and light is high.

Increasing light and temperature both accelerate strobilation in Aurelia labiata. If both temperature and insolation increase, then the effects could be additive, accelerating strobilation and jellyfish appearance. Such environmental changes would affect the seasonal production cycle similarly, so the ephyra production would be synchronized with their food supply. The main effect of a changing light regime would be to change the time of the seasonal appearance of jellyfish in coastal waters.

Little is known about the abundance or dynamics of most of the 1400 described species of gelatinous predators. In addition, many species are found in a wide range of environments. For example, even neighboring populations of Aurelia aurita have different seasonal dynamics (reviewed by Lucas 2001). Each population is adapted to local conditions, and their responses to changes may differ. We are only beginning to understand the causes of jellyfish and ctenophore blooms.

Acknowledgements. This research was funded by National Science Foundation (NSF) ADVANCE Fellows Award OCE0137419. This manuscript was prepared while the author was supported by grants from the National Science Council and the Ministry of Education of the Republic of China to W.T. Lo (NSC91-2621-Z 110-001 and 94-C030220 [Kuroshio project]). I greatly appreciate the help of several people who provided valuable assistance: for data collection, notably E.R. Marquardt, whose high school Honors Biology project was based on the first temperature-salinity (T-S) experiment, N.T. Schwarck, R.A. Hoover, and C. Collahan, and for data entry, G.P. Marquardt. Four MIMSUP (Multicultural Initiative in the Marine Sciences: Undergraduate Program) students (G. Arrondondo, S. Flores, G. Saluda, and R. Vazquez; and 2 REU (Research Experience for Undergraduate) students (E. Ninmann and T. Lederhouse; NSF grants 9731144, 0551898, and 0228618 to Western Washington University) conducted variations of these experiments.

\section{LITERATURE CITED}

Alley R, Berntsen T, Bindoff NL, Chen Z and 47 others (2007) Climate change 2007: the physical science basis, summary for policymakers: contribution of Working Group I to the 4th assessment report of the Intergovernmental Panel on Climate Change (IPCC). Available at www.ipcc.ch

Arai MN (1997) A functional biology of Scyphozoa. Chapman \& Hall, London

Arai MN (2005) Predation on pelagic coelenterates: a review. J Mar Biol Assoc UK 85:523-536

Attrill MJ, Wright J, Edwards M (2007) Climate-related increases in jellyfish frequency suggest a more gelatinous future for the North Sea. Limnol Oceanogr 52:480-485

Balzer I, Hardeland R (1996) Thermophotoperiodism. In: Greppin H, Degli Agosti R, Bonzon M (eds) Vistas on biorhythmicity. University of Geneva, p 37-50

Båmstedt U, Lane J, Martinussen MB (1999) Bioenergetics of ephyra larvae of the scyphozoan jellyfish Aurelia aurita in relation to temperature and salinity. Mar Biol 135:89-98 
Behrenfeld MJ, O'Malley RT, Siegel DA, McClain CR and 6 others (2006) Climate-driven trends in contemporary ocean productivity. Nature 444:752-755

Boero F, Bouillon J, Piraino S, Schmid V (2002) Asexual reproduction in the Hydrozoa (Cnidaria). In: Hughes RN (ed) Reproductive biology of invertebrates XI: Progress in asexual reproduction. Oxford \& IBH Publ Co, New Dehli, p 141-158

Boeuf G, Falcon J (2001) Photoperiod and growth in fish. Vie Milieu 51:247-266

Brodeur RD, Decker MB, Ciannelli L, Purcell JE, Bond NA, Stabeno PJ, Hunt GL Jr, Acuna E (in press) Rise and fall of jellyfish in the Bering Sea in relation to climate regime shifts. Prog Oceanogr

Butchart N, Austin J, Knight JR, Scaife A, Gallani ML (2000) The response of the stratospheric climate to projected changes in the concentrations of well-mixed greenhouse gases from 1992 to 2051. J Clim 13: 2142-2159

Cargo DG, King DR (1990) Forecasting the abundance of the sea nettle, Chrysaora quinquecirrha, in the Chesapeake Bay. Estuaries 13:486-491

Custance DRN (1964) Light as an inhibitor of strobilation in Aurelia aurita. Nature 204:1219-1220

Dawson MN, Martin LE, Penland LK (2001) Jellyfish swarms, tourists, and the Christ-child. Hydrobiologia 451:131-144

Faasse MA, Bayha KM (2006) The ctenophore Mnemiopsis leidyi A. Agassiz 1865 in coastal waters of the Netherlands: an unrecognized invasion? Aquat Invasions 1:270-277

Farnsworth E (2004) Hormones and shifting ecology throughout plant development. Ecology 85:5-15

Finenko GA, Kideys AE, Anninsky BE, Shiganova TA, Roohi A, Tabari MR, Rostami H, Bagheri S (2006) Invasive ctenophore Mnemiopsis leidyi in the Caspian Sea: feeding, respiration, reproduction and predatory impact on the zooplankton community. Mar Ecol Prog Ser 314: $171-185$

Genzano GN, Kubota S (2003) Synchronous mass release of mature medusae from the hydroid Halocordyle disticha (Hydrozoa, Halocordylidae) and experimental induction of different timing by light changes. Publ Seto Mar Biol Lab 39:221-228

Goy J, Morand P, Etienne M (1989) Long-term fluctuations of Pelagia noctiluca (Cnidaria, Scyphomedusa) in the western Mediterranean Sea. Prediction by climatic variables. Deep-Sea Res 36:269-279

Hamner WM, Jenssen RM (1974) Growth, degrowth, and irreversible cell differentiation in Aurelia aurita. Am Zool 14: 833-849

Hamner WM, Hamner PP, Strand SW (1994) Sun-compass migration by Aurelia aurita (Scyphozoa): population retention and reproduction in Saanich Inlet, British Columbia. Mar Biol 119:347-356

Hardeland R (1997) New actions of melatonin and their relevance to biometeorology. Int J Biometeorol 41:47-57

Hernroth L, Grøndahl F (1985) On the biology of Aurelia aurita (L.). 2. Major factors regulating the occurrence of ephyrae and young medusae in the Gullmar Fjord, western Sweden. Bull Mar Sci 37:567-576

Honegger T, Achermann J, Stidwill R, Littlefield L, Baenninger R, Tardent R (1980) Light-controlled spawning in Phialidium hemisphaericum (Leptomedusae). In: Tardent P, Tardent R (eds) Developmental and cellular biology of coelenterates. Elsevier/North-Holland Biomedical Press, Amsterdam, p 83-89

Ishii H, Watanabe T (2003) Experimental study of growth and asexual reproduction in Aurelia aurita polyps. Sessile Org 20:69-73
Leitz T (2001) Endrocrinology of the Cnidaria: state of the art. Zoology 103:202-221

Loeb MJ (1973) The effect of light on strobilation in the Chesapeake Bay sea nettle Chrysaora quinquecirrha. Mar Biol 20:144-147

Lu N, Liu C, Guo P (1989) Effect of salinity on larva of edible medusae (Rhopilema esculenta Kishinouye) at different development phases and a review on the cause of jellyfish resources falling greatly in Liaodong Bay. Acta Ecol Sin 9: 304-309

Lucas CH (2001) Reproduction and life history strategies of the common jellyfish, Aurelia aurita, in relation to its ambient environment. Hydrobiologia 451:229-246

Ma X, Purcell JE (2005) Temperature, salinity and prey effects on polyp versus medusa bud production of the invasive hydrozoan, Moerisia lyonsi. Mar Biol 147:225-234

Mechawar N, Anctil M (1997) Melatonin in a primitive metazoan: seasonal changes of levels and immunohistochemical visualization in neurons. J Comp Neurol 387: $243-254$

Mills CE (2001) Jellyfish blooms: are populations increasing globally in response to changing ocean conditions? Hydrobiologia 451:55-68

Molinero JC, Ibanez F, Nival P, Buecher E, Souissi S (2005) North Atlantic climate and northwestern Mediterranean plankton variability. Limnol Oceanogr 50:1213-1220

Naylor E (2006) Orientation and navigation in coastal and estuarine zooplankton. Mar Freshw Behav Physiol 39: $13-24$

Pallé E, Butler CJ (2002) The proposed connection between clouds and cosmic rays: cloud behaviour during the past 50-120 years. J Atmos Solar-Terr Phys 64:327-337

Pandi-Perumal SR, Srinivasan V, Maestroni GJM, Cardinali DP, Poeggeler B, Hardeland R (2006) Melatonin: Nature's most versatile biological signal? FEBS J 273:2813-2838

Parsons TR, Lalli CM (2002) Jellyfish population explosions: revisiting a hypothesis of possible causes. Mer 40:111-121

Purcell JE (2005) Climate effects on jellyfish populations. J Mar Biol Assoc UK 85:461-476

Purcell JE, Arai MN (2001) Interactions of pelagic cnidarians and ctenophores with fishes: a review. Hydrobiologia 451: $27-44$

Purcell JE, Decker MB (2005) Effects of climate on relative predation by scyphomedusae and ctenophores on copepods in Chesapeake Bay during 1987-2000. Limnol Oceanogr 50:376-387

Purcell JE, White JR, Nemazie DA, Wright DA (1999) Temperature, salinity and food effects on asexual reproduction and abundance of the scyphozoan Chrysaora quinquecirrha. Mar Ecol Prog Ser 180:187-196

Purcell JE, Shiganova TA, Decker MB, Houde ED (2001) The ctenophore Mnemiopsis in native and exotic habitats: US estuaries versus the Black Sea basin. Hydrobiologia 451: $145-176$

Purcell JE, Uye SI, Lo WT (2007) Anthropogenic causes of jellyfish blooms and direct consequences for humans. Mar Ecol Prog Ser (in press)

Raskoff KA (2001) The impact of El Niño events on blooms of mesopelagic hydromedusae. Hydrobiologia 451:121-129

Satheesh SK, Krishna Moorthy K (2005) Radiative effects of natural aerosols: a review. Atmos Environ 39:2089-2110

Spangenberg DB (1968) Recent studies of strobilation in jellyfish. Oceanogr Mar Biol Annu Rev 6:231-247

Spangenberg DB (1977) Aurelia metamorphosis: model system for study of thyroxine action. In: Grave GD (ed) Thyroid hormones and brain development. Raven Press, New York, p 151-166 
Spangenberg DB (1984) Effects of exogenous thyroxine on statolith synthesis and resorption in Aurelia. Am Zool 24: 917-923

Uye S, Ueta U (2004) Recent increase of jellyfish populations and their nuisance to fisheries in the inland Sea of Japan. Bull Jpn Soc Fish Oceanogr 68:9-19 (in Japanese)

Widmer C (2005) Effects of temperature on growth of north- east Pacific moon jellyfish ephyrae, Aurelia labiata (Cnidaria: Scyphozoa). J Mar Biol Assoc UK 85:569-573 Wild M, Gilgen H, Roesch A, Ohmura A and 6 others (2005) From dimming to brightening: decadal changes in solar radiation at Earth's surface. Science 308:847-850

Xian W, Kang B, Liu R (2005) Jellyfish blooms in the Yangtze Estuary. Science 307:41

Submitted: February 16, 2007; Accepted: May 16, 2007 Proofs received from author(s): September 17, 2007
Editorial responsibility: Otto Kinne (Editor-in-Chief), Oldendorf/Luhe, Germany 